This is the peer reviewed version of the following article:

Crivello, Gina and Jo Boyden (2014) 'On Childhood and Risk: An Exploration of Children's Everyday Experiences in Rural Peru', Children and Society 28 (5): 380-391, available online at http://onlinelibrary.wiley.com/doi/10.1111/j.1099-0860.2012.00465.x/pdf

This article may be used for non-commercial purposes in accordance with Wiley Terms and Conditions for self-archiving'. 


\title{
On Childhood and Risk: An exploration of children's everyday experiences in rural Peru
}

\author{
Gina Crivello and Jo Boyden
}

Keywords: risk; poverty; children's moralities; interdependencies; Peru

Corresponding author:

Gina Crivello

Department of International Development

University of Oxford

3 Mansfield Road

Oxford, OX1 3TB, UK

Tel: +44 (0)1865 281756

Email: gina.crivello@qeh.ox.ac.uk

Gina Crivello, PhD, is a Research Officer with Young Lives, based in the University of Oxford. Her research interests focus on children's daily lives within contexts of poverty, including how they negotiate their transitions to adulthood. She has addressed these questions in relation young people's experiences in Ethiopia, India, Peru and Morocco.

Jo Boyden is Director of Young Lives and Professor of International Development at the University of Oxford. Her research has mainly focused on children and childhood in contexts of armed conflict, forced migration and poverty. Most recently, she has been researching social risks among children in the context of household hardship in Ethiopia and India.

\section{Acknowledgements}

We are grateful to Young Lives children, families and communities for their ongoing collaboration. We thank Patricia Ames, Vanessa Rojas, Tamia Portugal and Natalia Streuli who led on fieldwork in Peru. Neha Batura and Karin Heissler provided invaluable research assistance in Oxford. An earlier and extended version of this article is available as a working paper, 'Situating Risk in Young People's Social and Moral Relationships: Young Lives Research in Peru' (2011) from www.younglives.org.uk. Young Lives is core-funded from 2001 to 2017 by UK aid from the UK Department for International Development (DFID) for the benefit of developing countries, and co-funded by the Netherlands Ministry of Foreign Affairs from 2010 to 2014. Sub-studies are funded by the Bernard van Leer Foundation, the Inter-American Development Bank (in Peru), the International Development Research Centre (in Ethiopia), and the Oak Foundation. The views expressed here are of the authors alone. 


\title{
On Childhood and Risk: An exploration of children's everyday experiences in rural Peru
}

\author{
Abstract \\ This article draws on data from a child poverty study in Peru to explore how poverty mediates a \\ multitude of risks in rural children's lives. It offers three main arguments. First, risk is not simply \\ a feature of 'extraordinary' childhoods and circumstances but also an integral part of everyday, \\ 'ordinary' lives. Second, social and moral dimensions of risk are crucial for shaping children's \\ responses to adversity. Third, where high levels of intra-familial dependence prevail, children \\ can make essential contributions to reducing household risk. Current approaches focus on so- \\ called 'objective' risks, but these often neglect children's own priorities and subjective \\ experiences.
}




\section{Introduction}

What does it mean for children to be 'in crisis' or 'at risk'? Definitions of crisis, risk and protection are contested and morally-laden. Popular images of 'children in crisis' feature a multitude of what are, it is hoped, extreme circumstances - children in situations of violent conflict or severe poverty, orphans, or victims of sexual abuse. That circumstances like hunger or parental death pose 'objective' risks to children is often taken as self-evident (Boyden 2009:8). However, such assumptions are rarely considered in relation to what children themselves identify as the main threats to their wellbeing or the ways they manage adversity in daily life (Scott et al 1998:700).

Poverty is commonly viewed as a crisis, characterized by deprivation and uncertainty. This article focuses on the way poverty mediates children's experiences of risk, in terms of how boys and girls make sense of the world around them and the difficulties they face, as well as their strategies for dealing with difficulties. The data were collected in Peru as part of Young Lives, an ongoing study into the dynamics of childhood poverty. [1]

We pursue three main lines of reasoning. The first centres on the argument that risk is not simply a feature of 'extraordinary' childhoods and circumstances but also an integral part of everyday, 'ordinary' lives in which the young negotiate multiple, interacting challenges. The second concerns the importance for children of the social and moral dimensions of risk and how these shape their engagement with adversity, including through providing opportunities for learning and growth. The third makes the case that in situations of strong intra-familial dependence 
children can play an important part in household risk reduction, their contributions at the same time impacting their roles and transitions to social adulthood.

\section{Risk research}

Whilst 'adversity' is about actual experiences of hardship or misfortune, 'risk' has more to do with future uncertainty (Tulloch and Lupton 2003: 17), what 'might be happening' (Adam et al 2000:2), and 'probabilities and not certainties' (Schoon 2006: 6-8). Risk has negative connotations and is thought to increase the probability of some undesirable outcome or of 'maladjustment' (Cicchetti \& Garmezy 1993; Masten et al. 1990).

That risk research remains heavily dominated by disciplines which deploy largely quantitative methods was confirmed by a database search of journal publications (14 February 2012) using ISI Web of Knowledge and the search terms 'risk and child*' and 'risk and youth', respectively. [2] Paediatrics and other medical sciences drive the study of 'child risk', constituting over two thirds of the results. Studies of 'youth risk' are concerned with psychological risk factors, risktaking behaviours, and criminality (over half of the articles) -- a traditional 'psycho-dynamic' approach whereby 'risk-taking is claimed to have linkages to biological and psychological developments in 'adolescence"' (France 2000: 317). Anthropological and other traditions that might emphasise risk as a social construct were largely absent from these results.

There is strong consensus in the medical and psychological literature that risk can be defined according to objective criteria, risks so classified impacting humans universally in similar ways. Particular attention is given to stressors experienced in the earliest years of life, and there is 
persuasive evidence that the impacts of specific material and nutritional deprivations can have physiological and neurological effects lasting into adulthood (Grantham-McGregor et al. 2007). For older children, the psychosocial impacts of poverty are especially important, as the sense of stigma, shame and social exclusion become more debilitating (Bartlett and Minujin 2009; Boyden et al 2003; Camfield 2010; Mann 2010; Ridge 2002; Tekola 2009).

Nonetheless, poverty should not be regarded as the sole defining feature of childhood in poor communities. Vigh (2008:5) has argued that for many people crisis is 'endemic rather than episodic and cannot be delineated as an aberrant moment of chaos or a period of decisive change', poverty thus becoming background or context over time. Important bodies of research within psychology and anthropology underscore the diversity of human responses to risk; resilience researchers point to individual traits that play out in complex gene/environment interdependencies (Curtis and Cicchetti 2003, Rutter 2002) and an array of family and community-level protective factors (Rutter 1985; Werner and Smith 2001).

Scholars in the social constructionist tradition stress social and cultural values as crucial in shaping meanings and responses to risk (Ungar 2005). In this tradition, Scott et al (1998:700) argue for situating risk within the contexts of children's everyday lives and activities, 'in the context of what children actually do, their journeys to and from school, their patterns of leisure, etc.'. For example, some cultures use moderate exposure to danger - such as in some rites of passage - to train their young in resilience (Boyden and Mann 2005:10). There is also a vital biographical dimension to the ways people respond to risk, being shaped by such factors as gender, age and social identity (Lupton and Tulloch 2002:332). 
We suggest that there is a strong moral dimension underlying ideas about what is 'harmful' and 'good' for children. Collective values are important for the effective social integration of the young and are learned from a very early age. For example, research by Rogoff shows (2003:226) how young children learn their community's moral order through the reactions of family members, teasing and shaming, and in playing games. From this, it can be seen that 'fitting in' and being respected within peer and family relationships are often core to children's everyday concerns and moral learning.

That said, it would be wrong to overemphasise continuity in norms and values, for children grow up in contexts that are dynamic, often presenting them with difficult contradictions and dilemmas. This requires acknowledging young people as agentive beings, in that boys and girls do not develop by merely absorbing collective norms and practice but through active construction of competencies and engagement with the world. In other words, children are social and moral actors in their own right and are continuously weighing up risks, making choices and negotiating strategies, with diverse outcomes (Frankel 2007:1).

\section{Current study}

This study examined 'risks' within the context of rural poverty and young people's everyday lives in Peru. Poverty remains a problem for the country, despite overall improvements in the economy and policy context since the cessation of political violence around two decades ago (Escobal et al 2008). Nearly half of the overall population was classified as poor in 2006 - three out of five children - and one in five were extremely poor. [3] Poverty is more prevalent in rural 
areas and amongst indigenous groups (Justino and Acharya 2003:11), and children's risk environments are shaped by these deeper structural inequalities.

Since 2002, Young Lives has been following nearly 700 Peruvian boys and girls born in 1994 through survey and qualitative research. [3] The study explores the causes and consequences, and children's changing experiences, of poverty. Fifty boys and girls, their parents and community members, participate in in-depth qualitative research. The research sample is 'propoor', consisting of children selected randomly from twenty survey sites, and a sub-sample of four qualitative research communities -- two of these, Rioja and Andahuaylas, are rural and are the primary focus of this article.

Rioja village is located in the upper Amazon jungle region in the northern part of the country. Many residents are Andean immigrants who raise cattle and farm (mainly coffee). Electricity reached the community in 2007 and the nearest location offering higher education is one hour's drive away. Andahuaylas is located in one of the country's poorest regions in the southern highlands, with lands 3,000 - 3,500 meters in altitude. Most inhabitants are indigenous Quechuaspeakers whose livelihoods consist of cattle-rearing and agriculture (mainly corn and potatoes). The nearest place for higher education is in the provincial capital, forty-five minutes away.

Qualitative research focuses on children's daily lives in poverty, including attitudes, aspirations and experiences. Methods include a combination of individual and collective semi-structured interviews, incorporating techniques such as drawing and mapping to facilitate conversations. For this paper, we coded thematically the complete set of individual and group interview 
transcripts from 2007 and 2008. Since we study boys and girls living in families, their risks are to a significant degree framed by household circumstances, so we draw on survey data to contextualise children's experiences and risks within wider household and community patterns.

\section{Poverty and risk in everyday context}

In this section we explore our first theme, which is the association between poverty and other risks for children in Peru. Despite recent impressive growth in Peru's national economy, there are remarkable disparities between rural and urban areas, between Spanish and non-Spanish speakers and across climatic zones, such that the poorest populations live in rural areas, in the highlands and in the rural jungle and speak indigenous languages (Sanchez 2008:1). In our sample, despite a reduction in poverty for rural households, growth has favoured urban households, and inequalities persist (Cueto et al 2011:9).

Patterned differences also exist in household exposure to 'shocks' which may impact negatively on children within households. [5] For example, economic and environmental shocks were more prevalent amongst rural households (compared to urban ones), poorer households (compared to wealthier ones) and indigenous households (compared to mestizo/mixed European and indigenous descent), and these attributes are intertwined. (See Table 1).

\section{TABLE 1: Distribution of Negative Household Shocks}

\begin{tabular}{|l|l|l|}
\hline & \multicolumn{2}{|l|}{$\%$ of households reporting shocks } \\
\hline & Economic shock & Environmental shock \\
\hline Rural & 22.0 & 52.2 \\
\hline
\end{tabular}




\begin{tabular}{|l|l|l|}
\hline Urban & 14.6 & 13.1 \\
\hline Poorest & 14.1 & 28.9 \\
\hline Least poor & 13.3 & 14.1 \\
\hline Indigenous & 22.0 & 50.8 \\
\hline Mestizo & 14.1 & 15.2 \\
\hline
\end{tabular}

(Source: Peru Young Lives Older Cohort Household Questionnaire 2009)

The findings suggest that some groups of children shoulder a greater burden of risk and that this is strongly shaped by household location and circumstances. Disparities are also evident in children's accounts of their time-use; aged 15, rural children generally spend more time than urban children working and less time in school. Rural girls spend the most time on unpaid work (caring for others, household chores), reporting around 8.5 more hours per week than urban girls. When paid and unpaid work are combined, rural boys spend on average 13.09 hours more per week working than urban boys. For many rural children then, poverty is an enduring circumstance and also mediates other risks.

Our qualitative data reveal considerable complexity with regard to children's engagement with risk. First, even though poverty pervades children's lives, boys and girls seldom emphasize material poverty directly in relation to risk or adversity, referring more often to poverty's effects in daily life. In this sense, poverty can be taken as 'background', a lens for understanding how young people manage their daily life choices and future aspirations rather than a specific, separable risk (Vigh 2008). 
We illustrate this point by citing an exchange with twelve year-old Atilio from Andahuaylas. [6] He drew and described what he imagined as 'happy' and 'sad' days for a boy like him. Atilio's household is among the poorest in our sample and poverty features clearly in his 'sad' account. When asked why the boy in his picture was crying, he explained: 'Because he wasn't helping his mother...and his mother whipped him [because] he didn't want to help in the fields...he didn't even want to go to school...[B]ecause he was anaemic...he didn't have the will.' The anaemia he attributed to the mother's poor cooking: '.. without meat and without vegetables... [because] she didn't have money.' In his representation, poverty clearly underpins and mediates several aspects of childhood risk but his starting point was the effects this had on his relationships.

Under circumstances of multiple, interacting risks it becomes very difficult to isolate, measure and rank individual risks in order of severity and/or specific child outcomes; the effects of 'extraordinary' events and situations are often expressed in terms of a diversity of impacts in daily life rather than through the articulation of deeper deprivations, sorrows or grief. This calls attention to the 'ordinary' ways in which children deal with a range of hardships. We explore this point through the case of twelve-year-old Nicolas who relates an 'extraordinary' personal crisis his father's death - to the daily risks associated with poverty and his changing responsibilities to his family. Nicolas' case fits the conventional risk profile, yet he manages his father's death in the ordinary ways that other children handle risks that matter to them but are often considered by the psychological literature to be mundane.

Nicolas lives in Rioja with his mother, step-father and younger sister. His elder sisters are maids in Lima. Their household was categorized amongst the poorest in our sample. Nicolas' father 
died when Nicolas was five-years old, and when he looked back at his life, aged twelve, there seems to be two phases to his narrative: a 'before my father died' and an 'after my father died'.

Nicolas explained that at one time the family was doing well. They owned a small shop, but it had to be closed when his father died, with significant detrimental economic impact on the family, forcing him and his sisters to work. Currently for Nicolas, possibly the main personal risk associated with the family's poverty is the threat it poses to his education; this concerns him far more than the work burden it entails. One of the main risks of poverty is psycho-emotional, rather than just material, in this case represented by the crushing of long-term aspirations. For many poor families, including Nicolas', education holds the promise of escaping poverty, of 'becoming somebody' in life, a pathway out of 'the fields' and away from the 'suffering' associated with agricultural work (Crivello 2011). Nicolas' mother tells him, 'what's of the fields stays fields; your studies, no one can take them away.'

Nicolas' case reflects another common feature of children's perceptions, insofar as risks are understood to be cumulative - increasing vulnerability over time- and connected. Children's everyday concerns came across strongly in group research on what it means for boys and girls in their communities to be doing well or badly in life. For example, in a discussion with twelveyear old girls in Rioja, Gloria drew a girl who, she said, was 'thinking too much', indicating that she was beset with worries, as documented in other studies with children living in difficult circumstances (cf. Hart et al 2006). The girl did not have her mother or any food to eat at home. Her father was an unemployed drunkard. The group discussed all of the drawings and agreed that the worst scenario was when a girl: 'doesn't have her mother; lacks food; her mother punishes 
her for being disobedient; she doesn't do her homework; and her father doesn't work, he's drunk'.

In contrast, doing well meant: 'being a good student, thus making parents happy; being obedient (by doing farm and housework); and respecting parents'. In this example, the girls viewed material adversity (e.g. not having anything to eat) as inter-twined with their social relationships. Discussions with girls in Andahuaylas had a similar focus, highlighting parental abandonment and family discord, with indicators for doing well also centring on familial relationships that supported their schooling. From these accounts it is evident that children in the study ground their perceptions of risk within the context of what matters most to them, namely having opportunities and support in school and good family relationships, these factors being viewed as mutually reinforcing their wellbeing.

\section{Social risks}

Our second argument is that poor children's experiences of risk need to be understood within the broader context and complexity of their social worlds and not narrowly focused on material needs. In making this case we point to two separate, but related, issues. First, children's sociomoral learning is regarded as key to their integration within family and community; therefore, challenges to this learning can be perceived as a greater threat to children's wellbeing than material deficit. Second, adults in rural communities are not able to shield the young from poverty and other adversities and are often of the view that boys and girls grow morally and socially and acquire crucial life skills by working and helping alleviate household hardship. In other words, it is accepted that learning can take place in contexts of risk. 
Beginning with the first issue, rural families place considerable emphasis on children developing as sense of responsibility, respect for others and obedience, such attributes supporting young people's transitions to adulthood. This is illustrated by Nicolas' mother whose concerns for her children are not limited to the family's material needs but involve vital moral considerations:

[W]hen they were made orphans, the first thing we taught him [Nicolas] was to weed, to gather coffee... to wash his clothes...that he learns how to show respect, that he doesn't talk bad about his teachers, or about people in general.

It is important to her that Nicolas grows up to be responsible and respectful, no matter his circumstances, 'I tell him not to pay attention to what people say, even if they call you 'orphan', you be good, a good young man .'

In this way, as children negotiate their evolving sense of self and of social belonging, they manage a range of social expectations and often come to share these understandings. Discussions outlined above with the girls' groups illustrate this, where attributes like obedience and respect were perceived as key ingredients in personal wellbeing and domestic harmony. Concurrently, failure to meet expectations around family roles and responsibilities were at the forefront of their accounts of illbeing and risk. Likewise, the choices that families make as they confront difficulties impact on their interdependence and on the quality of their social bond. For example, when Rodrigo's mother was asked who is responsible for deciding whether children remain at or drop out of school, her response underscored a sense of moral duty:

[W]hen they're young, you have to stay on top of them for their own good. When they're grown up, they ask their parents, 'Why didn't I study? ... [now] I don't know 
anything, I'm useless'. That's why it's important to insist that they study when they're young.

Such concerns may reflect mothers' judgements about their own childhood histories:

When they're grown up they're going to ask their parents, “Why didn't you make me study?", because that's what we ask our own parents now.

In rural communities, responsibilities for managing risks in childhood are therefore often shared across the generations.

In both villages, there are high aspirations for children's education and future careers, including finishing secondary school, going to university and becoming a 'professional'. Schooling may be perceived as the prime route out of both individual and collective poverty in the longer term, but children's work is also valued highly, work and school offering different protections for the young and for their families.

Boys and girls who work with their families may be given the occasional 'tip', but many also work on other people's land for pay, keeping some of their earnings for personal expenses, giving the remainder to their mothers. 'Not having to ask my mother for money' was widely cited as a benefit of paid work. Children also feel that the work they did at this age prepares them for future adult work, and it prevents them from growing lazy or irresponsible. Decisions around how children should spend their time are therefore informed by both material and moral imperatives. Hence, children's work supports their families in the here-and-now, by relieving household economic pressures, and their school aspirations and participation fulfil longer-term individual and family goals. 
Turning to the second issue, the idea that risk holds potential for enhancing children's social learning derives from the importance attached to developing children's self-reliance, which in turn strengthens their capacity to contribute to their households. This is what Rogoff (2003) has referred to as 'interdependent autonomy'. In contexts of poverty and insecurity, participation in work is commonly seen as a means of guaranteeing that children become responsible and selfreliant, skills viewed as essential 'insurance' against risk. With the expansion of formal schooling, education is also increasingly understood to play a part in risk reduction. However, while education is an investment in a child's or family's future and in long-term poverty reduction, children's work has a more immediate role in mitigating risk. But the relationship between children's work and risk is not straightforward. On the one hand, work can be essential to the domestic economy, whereas on the other, it can also represent a risk to the young.

The idea that child work may be essential to children's development and a means for preventing personal and household destitution is especially prevalent in rural areas of the country. For example, a survey of the perceptions of 1000 adults (Sulmont Haak 2007) found that children's work is generally more acceptable in rural areas. 'Responsibility' is a core value for boys and girls to learn, and it was widely reported that children who work 'become more responsible'. Based on ethnographic research in a Peruvian herding community, Bolin (2006:62) also emphasises the importance of placing children's work within the context of local social and moral values and in their daily play and learning. She observes that children's strong work ethic is shaped by respect, pride and survival strategies, the harsh living environment requiring the participation of boys and girls from a very young age. 
The majority of children in our rural qualitative sample provide essential labour to their households and over time learn to become more self-reliant by taking on ever greater work responsibilities. In the survey, by age 12 rural children report for a 'typical day' carrying out more work (and spending less time in school and at play) than do urban children (Table 2).

Table 2: Boys' and Girls' Daily Time-use by Location (Age 12)

\begin{tabular}{|l|c|c|c|c|}
\hline \multicolumn{1}{|c|}{ In minutes } & Boys & Girls & Boys & Girls \\
\hline Caring for others & 68 & 74 & 76 & 93 \\
\hline Domestic tasks & 130 & 132 & 131 & 151 \\
\hline $\begin{array}{l}\text { Family } \\
\text { farm/business }\end{array}$ & 31 & 24 & 97 & 95 \\
\hline $\begin{array}{l}\text { Paid work outside } \\
\text { home }\end{array}$ & 10 & 13 & 32 & 18 \\
\hline (all above work) & 239 & 243 & 336 & 357 \\
$(3 h, 59$ min $)$ & $(4 h, 3$ min $)$ & $(5 h, 36$ min $)$ & $(5 h, 57$ min $)$ \\
\hline At school & 304 & 306 & 260 & 258 \\
\hline Play & 173 & 197 & 146 & 127 \\
\hline
\end{tabular}

(Source: 2006 Young Lives Older Cohort Child Questionnaire)

Children's work and household contributions have also been shown in our study to allay adult concerns about children's fate in the context of future uncertainty; for example, work affords children practical skills that would enable them to 'fend for themselves' in the case of pre-mature parental death or sudden illness.

Here we highlight the potential 'positive' dimensions of risk; as boys and confront difficult choices they can 'prove' themselves in the eyes of others (for example, as mature, as a good son or daughter, as responsible). In this way, the link between child work and social responsibility 
can be regarded as crucial to children's effective transition to adulthood as well as to household risk reduction.

\section{Children's engagement with risk}

Our third theme concerns the ways in which risk mitigation frames children's roles, choices and transitions to social adulthood. We have seen that working to prevent and/or overcome risk is necessarily an ongoing process for many rural households in this study.

We have also suggested that mitigating risk is most often a collective rather than individual responsibility and requires children's participation. Work roles commonly respond to events and circumstances affecting the household, such as economic shocks experienced by the wider community. For example, in 2008, several families in Andahuaylas struggled to cope with the rising cost of living, coupled with poor annual rains. Boys and girls who in the previous year had not been working for pay sought out paid work. This was the case for fourteen year-old Esmeralda who lived with her mother and grandmother, most of her siblings having migrated to Lima for work. Esmeralda started working as a farm hand on weekends and holidays, earning around 3.5 US dollars for a full-day's work. She was able to cover costs for schooling, clothing and food, thus saving her mother these expenses. Esmeralda, like many of the young people in our study, did not mention the community's economic crisis as a reason for her starting work; however, this was a major concern for her mother:

[W] 're struggling to get by (nada nos alcanza para vivir). Everything's so expensive... we're so worried because there's nothing for our survival... sugar, salt, oil, it's all gone up. 
Such concerns were common amongst parents and although we would expect the demand for children's work in this context to increase as they grow older, adverse circumstances can precipitate these social processes.

Other risks were idiosyncratic, such as household illness or parental migration, this often requiring the flexibility of family groups to ensure survival. For example, when Atilio's father (from Andahuaylas) migrated in search of work, Atilio, his siblings and their mother redistributed their work roles, each increasing the time spent working on their farm. Maria and her sister (Rioja) began providing vital care for their mother who had become ill: 'We prepare the meals, get her medication ready, go to buy her pills.' Their contributions were valued under the circumstances and both girls began working weekends in the city, Maria clearing tables in her uncle's pool hall and her sister assisting food vendors in the market.

Thus, young people's roles, responsibilities and capacities, as well as their perceptions of the risks they confront, evolve as they grow up and respond to household composition and demands (Punch 2001). Many children reported that they were feeding the family's small animals and carrying water and firewood home by age three or four, often accompanying older siblings or adults in their work. Between six and eight years old they began caring for younger siblings, working on the family farm, and girls especially, began to engage in family meal preparation. By age twelve, many of them were balancing school with several household responsibilities and paid work during weekends and school holidays. Although at this age boys and girls carry out similar tasks at home and in the fields, girls tend to spend more time around the home, whereas boys experience greater mobility (Ames et al 2009: 18). Children described their acquisition of 
responsibility as a gradual process and their transitions to adulthood were not defined by a single threshold or age demarcation.

Gender differences become more prominent in the early teen years, and the risks facing this age group also become more gendered, sexualised and of a social character. Maria's mother (Rioja) referred to some of the girls in the community who had become mothers by the age of 12 or 13 , this making her fear for Maria's future. Getting 'tricked' (engañarse) by a boy or falling in love are viewed as major risks for girls since early pregnancy can derail aspirations for professional careers and limit life chances. Mothers also worry about boys succumbing to negative peer pressure, like Atilio's mother who feared that he might be influenced to drop out of school. All of this places increased moral responsibility on the young to make choices that do not jeopardize their wellbeing or future prospects.

\section{Discussion}

In this article we have argued that in much of the dominant medical and psychology literature risk is presumed as fact, as a discrete threat embodying certain objective criteria. The research we have presented highlights a very different situation in which poverty is a pervasive feature and background to daily life for rural children and their households in our study sample. Although not often articulated by children directly as an adversity, poverty contributed significantly to household insecurity and also mediates a diversity of other risks. The households and communities in which children grow up influence their exposure to risk as well as the expectations for how they should manage the difficulties they encounter. We also argued that the risks that boys and girls face and their ways of responding are often strongly shaped by their 
individual biographies, including their gender, age and family history. In other words, in this context, 'poverty' is not an 'event' or a separable risk, and children often struggle with multiple interacting risks, many or most of which are ongoing.

It has been shown that mitigating risk is most often a collective rather than an individual responsibility, with children playing important roles. Fulfilling their responsibilities involves moral competencies, maturity and mastery of basic life skills. Thus, families expect their young to develop attributes are especially valued such as self-reliance, responsibility and respect. Children's work and schooling are viewed as vital means whereby boys and girls become competent moral and social actors, enabling them to contribute to household poverty mitigation, and constituting an 'insurance' against other risks such as the death or illness of a household member or an economic downturn.

There is also a life course dimension to this, as young people face myriad risks and choices in their transition to adulthood. These 'choice points' can be seen as opportunities for the young as social agents to demonstrate to others their evolving sense of responsibility and autonomy, or to risk failure. Coping with adversity may precipitate children's transition to proto-adulthood and undermine their schooling, with the attendant possibility of introducing new risks into their lives. It is therefore important to acknowledge the social and moral responsibilities which young people must manage amongst the other challenges of growing up in poverty. Often they confront risk within a context of 'thin agency' - the 'decisions and everyday actions that are carried out within highly restrictive contexts, characterised by few viable alternatives' (Klocker: 2007: 85). It is within this framework that we might better assess and acknowledge the complex decision- 
making processes involved in children's transition to adulthood, such as the reasons why they work or choose to leave school.

In this way, risk can be seen as having an important part to play in shaping children's social and moral identities; in other words, by making effective decisions and assuming a constructive role in adversity, boys and girls may prove themselves to others. Even 'extraordinary' adversities, such as parental death, are often managed by children through everyday processes, within familiar domains and in intimate family and peer relationships. Social risks are therefore at the forefront of children's concerns and merit far greater attention than they receive in the literatures currently dominating this area of research.

\section{Endnotes}

1. See www.younglives.org.uk.

2. The 300 most recent articles from each search were sorted by discipline.

3. Based on Sanchez (2008) using the definition established by the National Bureau of Statistics (INEI).

4. For sampling strategy see Escobal and Flores (2008).

5. Economic shocks include increased input prices, decreased output prices, livestock death, job loss, and land disputes. Environmental shocks include drought, flooding, frost, etc.

6. Pseudonyms are used. 


\section{References}

Adam, B., Beck, U., \& van Loon, J. (2000). The risk society and beyond: Critical issues for social theory (ed) London: SAGE.

Ames, P, Rojas, V., \& Portugal, T. (2009). Young Lives qualitative research: Peru - Round 1. Young Lives Technical Note no. 18.

Bartlett, S. \&Minujin, A. (2009). The everyday environments of children's poverty. Children, Youth and Environments, 19(2), 1-11.

Bolin, I. (2006). Growing up in a culture of respect: Child rearing in Highland Peru. Austin, TX: University of Texas Press.

Boyden, J. (2009). Risk and capability in the context of adversity: Children's contributions to household livelihoods in Ethiopia. Children, Youth and Environments, 19 (2), 111-137.

Boyden, J., Eyber, C., Feeny, T. \& Scott, C. (2003). Children and poverty: Experiences and perceptions from Belarus, Bolivia, India, Kenya and Sierra Leone. Virginia: Christian Children's Fund.

Boyden, J. \& Mann, G. (2005). Children's risk, resilience and coping in extreme situations. In M. Ungar (Ed.). Handbook for Working with Children and Youth: Pathways to Resilience across Cultures and Contexts (pp 3-25). Thousand Oaks: Sage Publications.

Camfield, L. (2010). 'Stew without bread or bread without stew': Children's understandings of poverty in Ethiopia. Children and Society, 24(4), 271-281.

Cicchetti, D., \& Garmezy, N. (1993). Milestones in the development of resilience. Development and Psychopathology, 5(4), 497-502.

Crivello, G. (2011) 'Becoming somebody': youth transitions through education and migration in Peru. Journal of Youth Studies. 
Cueto, S., Escobal, J., Penny, M. And Ames, P. (2011) Tracking Disparities: Who gets left behind? Initial findings from Peru Round 3 Survey.

Curtis, J., \& Cicchetti, D. (2003). Moving research on resilience into the 21st century:

Theoretical and methodological considerations in examining the biological contributors to resilience. Development and Psychopathology, 15, 773-810.

Escobal, J., Ames, P., Cueto, S., Penny, M., \& Flores, E. (2008). Young Lives: Peru Round 2 Survey.

Escobal, J. \& Flores, E., (2008). An Assessment of the Young Lives Sampling Approach in Peru, Technical Note 3, Young Lives: Oxford.

France, A. (2000). Towards a Sociological Understanding of Youth and their Risk-taking. Journal of Youth Studies, 3:3, 317-331.

Frankel, S. (2007). Researching children's morality: Developing research methods that allow children's involvement in discourses relevant to their everyday lives. Childhoods Today, 1(1),125.

Grantham-McGregor, S., Cheung, Y.B., Cueto, S., Glewwe, P., Richter, L. \& Strupp, B. (2007). Child development in developing countries: Development potential in the first 5 years for children in developing countries. The Lancet, 369, 60-70.

Hart, J., Boyden, J., de Berry, J. \& Feeny, T., (2006). Children affected by armed conflict in South Asia: a review of trends and issues identified through secondary research. In Reyes, G. \& Jacobs, G.A., (Eds.), Handbook of international disaster psychology: interventions with special needs populations (pp. 61-76).Westport: Praeger Publishers.

Justino, P. \& Acharya, A. (2003). Inequality in Latin America: Processes and inputs, PRUS Working Paper No. 22, Brighton: Poverty Research Unit at Sussex. 
Klocker, N. (2007). An example of 'thin' agency. Child domestic workers in Tanzania. In Panelli, R., Punch, S., \& Robson, E., (Eds.), Global perspectives on rural childhood and youth: young rural lives (pp. 83-94). New York: Routledge.

Lupton, D. \& Tulloch, J. (2002). 'Risk is part of your life’' Risk epistemologies among a group of Australians. Sociology, 36(2), 317-334.

Mann, G. (2010). 'Finding a life' among undocumented Congolese refugee children in Tanzania. Children and Society, 24(4), 261-270.

Masten, A., Best, K., \& Garmezy, N. (1990). Resilience and development: Contributions from the study of children who overcome adversity. Development and Psychopathology, 2, 425-444. Ridge, T. (2002). Childhood poverty and social exclusion: From a child's perspective. Bristol, UK: The Policy Press.

Rogoff, B. (2003). The Cultural nature of human development. Oxford: Oxford University Press. Rutter, M. (1985). Resilience in the face of adversity: Protective factors and resistance to psychiatric disorder. British Journal of Psychiatry, 147, 598-611.

Rutter, M. (2002). Nature, nurture, and development: From evangelism through science toward policy and practice. Child Development, 73(1), 1-21.

Sanchez, A. (2008). Childhood poverty in Peru: An annotated literature review, Technical Note 8, Young Lives: Oxford.

Schoon, I. (2006). Risk and resilience. Cambridge: Cambridge University Press.

Scott, S., Jackson, S., \& Backett-Milburn, K. (1998). Swings and roundabouts: the impact of 'risk anxiety' on the everyday worlds of children. Sociology, (32)4, 689-705.

Sulmont Haak, D. (2007). Trabajo Infantil: Estudio de opinión pública en el Peru. Lima: OIT. 
Tekola Gebru, B. (2009). Looking beyond poverty: Poor children's perspectives and experiences of hazard, coping, and resilience in Addis Ababa. Thesis ( $\mathrm{PhD})$. University of Bath. Tulloch, J. \& Lupton, D. (2003). Risk and everyday life. London: Sage Publications. Ungar, M. (2005). Introduction: Resilience across cultures and contexts. In: M. Ungar (Ed.), Handbook for working with children and youth: Pathways to resilience across cultures and contexts (pp. xv-xxxix). Thousand Oaks: Sage Publications.

Vigh, H. (2008). Crisis and chronicity: Anthropological perspectives on continuous conflict and decline. Ethnos, 73(1), 5-24.

Werner, E. \& Smith, R. (2001). Journeys from Childhood to Midlife: Risk, Resilience and Recovery. Ithaca: Cornell University Press. 